\title{
The Overall Effects of AlN Nanoparticle Addition to Hybrid Magnesium Alloy AZ91/ZK60A
}

\author{
Muralidharan Paramsothy, ${ }^{1}$ Jimmy Chan, ${ }^{2}$ Richard Kwok, ${ }^{2}$ and Manoj Gupta ${ }^{1}$ \\ ${ }^{1}$ Department of Mechanical Engineering, National University of Singapore, 9 Engineering Drive 1, Singapore 117576 \\ ${ }^{2}$ CTO Office, Singapore Technologies Kinetics Ltd (ST Kinetics), 249 Jalan Boon Lay, Singapore 619523
}

Correspondence should be addressed to Manoj Gupta, mpegm@nus.edu.sg

Received 5 December 2011; Accepted 11 February 2012

Academic Editor: Hongmei Luo

Copyright (c) 2012 Muralidharan Paramsothy et al. This is an open access article distributed under the Creative Commons Attribution License, which permits unrestricted use, distribution, and reproduction in any medium, provided the original work is properly cited.

\begin{abstract}
A hybrid magnesium alloy nanocomposite containing AlN nanoparticle reinforcement was fabricated using solidification processing followed by hot extrusion. The nanocomposite exhibited similar grain size to the monolithic hybrid alloy, reasonable $\mathrm{AlN}$ and intermetallic nanoparticle distribution, nondominant $\left(\begin{array}{llll}0 & 0 & 0 & 2\end{array}\right)$ texture in the longitudinal direction, and $17 \%$ higher hardness than the monolithic hybrid alloy. Compared to the monolithic hybrid alloy, the nanocomposite exhibited higher tensile yield strength $(0.2 \%$ TYS) and ultimate tensile strength (UTS) without significant compromise in failure strain and energy absorbed until fracture (EA) $(+5 \%,+5 \%,-14 \%$ and $-10 \%$, resp.). Compared to the monolithic hybrid alloy, the nanocomposite exhibited unchanged compressive yield strength $(0.2 \%$ CYS $)$ and higher ultimate compressive strength (UCS), failure strain, and EA $(+1 \%,+6 \%,+24 \%$, and $+6 \%$, resp. $)$. The overall effects of AlN nanoparticle addition on the tensile and compressive properties of the hybrid magnesium alloy is investigated in this paper.
\end{abstract}

\section{Introduction}

Compared to aluminium, magnesium is the lightest structural metal (35\% lighter) used in many engineering applications today $[1,2]$. Commercially available magnesium alloys are suitable for actual or potential use regarding weightcritical applications in the automotive, aerospace, civil infrastructure, building and construction, defence, biomedical, and sports/recreational industries $[1,3]$. In the World War 2 era, Mg-Zn alloy parts were economically manufactured and heavily used in aircraft [3]. Soon after the world war, $\mathrm{Mg}-\mathrm{Al}$ alloys were also economically developed with specific metallurgical advantages over Mg-Zn alloys [3]. At present, $\mathrm{Mg}-\mathrm{Y}$ and Mg-RE (Rare Earth) alloys are in development for even more specific metallurgical advantages but at generally higher cost compared to Mg-Zn and Mg-Al alloys [1]. Regardless of cast or wrought forms, $\mathrm{Mg}-\mathrm{Zn}$ and $\mathrm{Mg}-\mathrm{Al}$ alloys each still remain as the main classes of $\mathrm{Mg}$ alloys commercially in use. In the wrought form, the Mg alloys have good strength and ductility. However, wrought $\mathrm{Mg}-\mathrm{Zn}$ and $\mathrm{Mg}-\mathrm{Al}$ alloy nanocomposites have often demonstrated simultaneously higher strength and ductility compared to the monolithic alloys [4-14]. Additionally, friction stir processed Mg$\mathrm{Al}$ nanocomposites have also demonstrated higher hardness and strength than the corresponding monolithic alloys [1518]. Based on much of the existing representative research literature on solidification processed magnesium alloy nanocomposites, good nanoparticle distribution can be achieved in the magnesium matrix and better mechanical properties can be achieved due to the addition of nanoparticles [418]. However, it is the addition of oxide- or carbon-based nanoparticles to magnesium alloys as opposed to nitridebased nanoparticle addition that most of the research literature currently discusses. In the context of magnesium composite processing, the magnesium-oxygen strong affinity and magnesium-carbon weak affinity (comparative to each other) are both well known. On the other hand, what is not known is the affinity between magnesium and nitrogen concerning effects in magnesium nanocomposite processing (let alone solidification processing). 
Accordingly, one of the primary aims of this study was to simultaneously increase tensile strength and ductility of AZ91/ZK60A hybrid magnesium alloy with AlN nanoparticles. Another aim of the present study was to evaluate the compressive properties of AZ91/ZK60A/AlN hybrid alloy nanocomposite. Disintegrated melt deposition (DMD) [19, 20] followed by hot extrusion was used to synthesize the AZ91/ZK60A/AlN hybrid alloy nanocomposite.

\section{Experimental Procedures}

2.1. Materials. In this study, AZ91 (nominally 8.309.70 wt.\% Al, $0.35-1.00$ wt.\% Zn, $0.15-0.50$ wt.\% Mn, 0.10 wt.\% Si, 0.030 wt.\% Cu, 0.005 wt.\% Fe, 0.002 wt.\% $\mathrm{Ni}, 0.02$ wt.\% others, balance $\mathrm{Mg}$ ) and ZK60A (nominally 4.80-6.20 wt.\% Zn, 0.45 wt.\% Zr, balance Mg), both alloys supplied by Tokyo Magnesium Co. Ltd. (Yokohama, Japan) were used as matrix material. 3 parts AZ91 were mixed with 1 part ZK60A by mass to metallurgically downgrade AZ91. The intention of this mixing was to decrease the nominal aluminium content of AZ91 by 2 wt.\%. AZ91 and ZK60A blocks were sectioned to smaller pieces. All oxide and scale surfaces were removed using machining. All surfaces were washed with ethanol after machining. AlN nanoparticles (99\% purity, spherical, $10-20 \mathrm{~nm}$ size) supplied by Nanostructured \& Amorphous Materials Inc (TX, USA) were used as the reinforcement phase.

2.2. Processing. Monolithic AZ91/ZK60A hybrid alloy (nominal aluminium content of AZ91 decreased by $2 \mathrm{wt. \%}$.) was cast using the DMD method $[19,20]$. This involved heating AZ91 and ZK60A blocks to $750^{\circ} \mathrm{C}$ in an inert Ar gas atmosphere in a graphite crucible (A12 designated size of top OD: $171 \mathrm{~mm}$, bottom OD: $121 \mathrm{~mm}$, height: $210 \mathrm{~mm}$ ) using a resistance heating furnace. The crucible was equipped with an arrangement for bottom pouring. Upon reaching the superheat temperature, the molten slurry was stirred for $2.5 \mathrm{~min}$ at $460 \mathrm{rpm}$ using a twin blade (pitch $45^{\circ}$ ) mild steel impeller to facilitate the uniform distribution of heat. The impeller was coated with Zirtex $25\left(86 \% \mathrm{ZrO}_{2}, 8.8 \% \mathrm{Y}_{2} \mathrm{O}_{3}\right.$, $3.6 \% \mathrm{SiO}_{2}, 1.2 \% \mathrm{~K}_{2} \mathrm{O}$ and $\mathrm{Na}_{2} \mathrm{O}$, and $0.3 \%$ trace inorganics) to avoid iron contamination of the molten metal. The melt was then released through a $10 \mathrm{~mm}$ diameter orifice at the base of the crucible. The melt was disintegrated by two jets of argon gas oriented normal to the melt stream located $265 \mathrm{~mm}$ from the melt pouring point. The argon gas flow rate was maintained at $25 \mathrm{lpm}$. The disintegrated melt slurry was subsequently deposited onto a metallic substrate located $500 \mathrm{~mm}$ from the disintegration point. An ingot of $40 \mathrm{~mm}$ diameter was obtained following the deposition stage. To form the AZ91/ZK60A/1.5 vol\% AlN hybrid alloy nanocomposite, AlN nanoparticle powder was isolated by wrapping in $\mathrm{Al}$ foil of minimal weight $(<0.50 \mathrm{wt} . \%$ with respect to AZ91 and ZK60A total matrix weight) and arranged on top of the AZ91 and ZK60A alloy blocks (see Figure 1), with all other DMD parameters unchanged. All billets were machined to $35 \mathrm{~mm}$ diameter and hot-extruded using 20.25:1 extrusion ratio on a 150 ton hydraulic press. The extrusion temperature was $350^{\circ} \mathrm{C}$. The billets were held at $400^{\circ} \mathrm{C}$ for $60 \mathrm{~min}$ in a

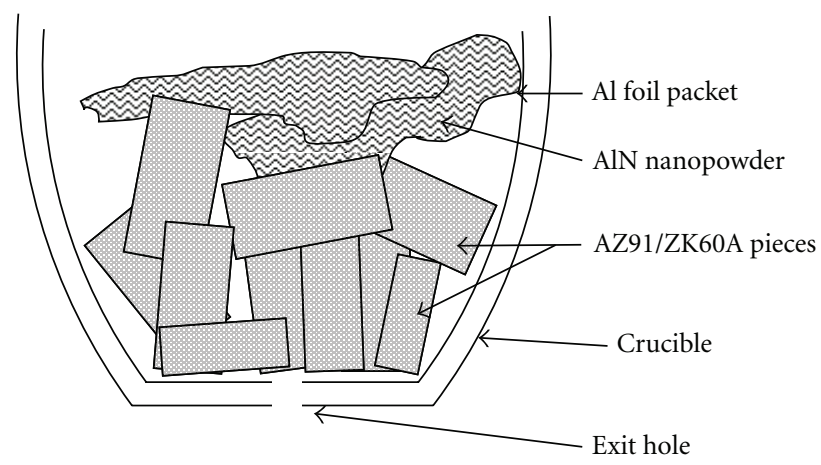

FIGURE 1: Arrangement of raw materials in crucible before casting for AZ91/ZK60A/AlN nanocomposite.

furnace prior to extrusion. Colloidal graphite was used as a lubricant. Rods of $8 \mathrm{~mm}$ were obtained.

2.3. Heat Treatment. Heat treatment was carried out on all extruded sections at $200^{\circ} \mathrm{C}$ for 1 hour using a resistance heating furnace. This selection of temperature and time was made in order to relax the monolithic AZ91/ZK60A hybrid alloy (nominal aluminium content of AZ91 decreased by 2 wt.\%.) without recrystallization softening. The recrystallization temperature of AZ61 magnesium alloy (as the nearest matching alloy in terms of composition) following $20 \%$ cold work after 1 hour is $288^{\circ} \mathrm{C}$ [1]. Prior to heat treatment, the sections were coated with colloidal graphite and wrapped in aluminum foil to minimize reaction with oxygen present in the furnace atmosphere.

2.4. Microstructural Characterization. Microstructural characterization studies were conducted on metallographically polished monolithic and nanocomposite extruded samples to determine grain characteristics. Hitachi S4300 FieldEmission SEM (FESEM) was used. Image analysis using Scion software was carried out to determine the grain characteristics. Thin foils were prepared from the monolithic and nanocomposite extruded samples for transmission electron microscopy (TEM) using disc punch-out and ion-milling for nanoparticle distribution observation (regarding localized effects). Goniometer XRD studies were conducted using $\mathrm{CuK}_{\alpha}$ radiation $(\lambda=1.5406 \AA)$ with a scan speed of $2^{\circ} / \mathrm{min}$ in an automated Shimadzu LAB-X XRD-6000 diffractometer to determine intermetallic phase(s) presence and dominant textures in the transverse and longitudinal (extrusion) directions (regarding globalised effects).

2.5. Hardness. Microhardness measurements were made on polished monolithic and nanocomposite extruded samples. Vickers microhardness was measured with an automatic digital Shimadzu HMV Microhardness Tester using 25 gfindenting load and $15 \mathrm{~s}$ dwell time.

2.6. Tensile Testing. Smooth bar tensile properties of the monolithic and nanocomposite extruded samples were determined based on ASTM E8M-05. Round tension test 
TABLE 1: Results of grain characteristics and microhardness of AZ91/ZK60A and AZ91/ZK60A/AlN nanocomposite.

\begin{tabular}{lcccc}
\hline Material & $\begin{array}{c}\text { AlN } \\
(\text { vol.\%) }\end{array}$ & \multicolumn{2}{c}{$\begin{array}{c}\text { Grain characteristics } \\
\text { Size }(\mu \mathrm{m})\end{array}$} & $\begin{array}{c}\text { Aspect ratio } \\
\text { Microhardness } \\
(\mathrm{HV})\end{array}$ \\
\hline $\begin{array}{l}\text { AZ91/ZK60A } \\
\text { AZ91/ZK60A/ }\end{array}$ & - & $4.5 \pm 0.9$ & 1.4 & $137 \pm 4$ \\
1.5 vol\% AlN & 1.50 & $4.2 \pm 0.8$ & 1.4 & $160 \pm 8(+17)$ \\
\hline
\end{tabular}

${ }^{\mathrm{a}}$ Based on approximately 100 grains.

() Brackets indicate \% change with respect to corresponding result of AZ91/ZK60A.

samples of $5 \mathrm{~mm}$ diameter and $25 \mathrm{~mm}$ gauge length were subjected to tension using an MTS 810 machine equipped with an axial extensometer with a crosshead speed set at $0.254 \mathrm{~mm} / \mathrm{min}$.

2.7. Compressive Testing. Compressive properties of the monolithic and nanocomposite extruded samples were determined based on ASTM E9-89a. Samples of $8 \mathrm{~mm}$ length $(l)$ and $8 \mathrm{~mm}$ diameter $(d)$ where $l / d=1$ were subjected to compression using a MTS 810 machine with $0.005 \mathrm{~min}^{-1}$ strain rate.

\section{Results}

3.1. Macrostructural Characteristics. No macropores or shrinkage cavities were observed in the cast monolithic and nanocomposite materials. No macrostructural defects were observed for extruded rods of monolithic and nanocomposite materials.

3.2. Microstructural Characteristics. Microstructural analysis results revealed that grain size and aspect ratio remained statistically unchanged in the case of nanocomposite as shown in Table 1 and Figures 2(a) and 2(b). Grain size refers to diameter of the grain assuming it is circular in shape. AlN nanoparticle reinforcement and fine intermetallic particle distributions in the nanocomposite were reasonably uniform as shown in Figure 2(c).

Texture results are listed in Table 2 and shown in Figure 3. In monolithic and nanocomposite materials, the dominant texture in the transverse and longitudinal directions was $\left(\begin{array}{llll}1 & 0 & -1 & 1\end{array}\right)$. Here, extrusion did not result in the $\left(\begin{array}{llll}0 & 0 & 0 & 2\end{array}\right)$ plane being intensely parallel to the extrusion direction (as we have previously reported) [6-14].

3.3. Hardness. The results of microhardness measurements are listed in Table 1. The nanocomposite exhibited higher hardness than the monolithic material.

3.4. Tensile Behavior. The overall results of ambient temperature tensile testing of the extruded materials are shown in Table 3 and Figure 4(a). The strength of AZ91/ZK60A/ $1.5 \mathrm{vol} \%$ AlN was higher compared to monolithic AZ91/ ZK60A, without significant compromise in failure strain and energy absorbed until fracture (EA). EA was determined by
TABLE 2: Texture results of AZ91/ZK60A and AZ91/ZK60A/AlN nanocomposite based on goniometer X-ray diffraction.

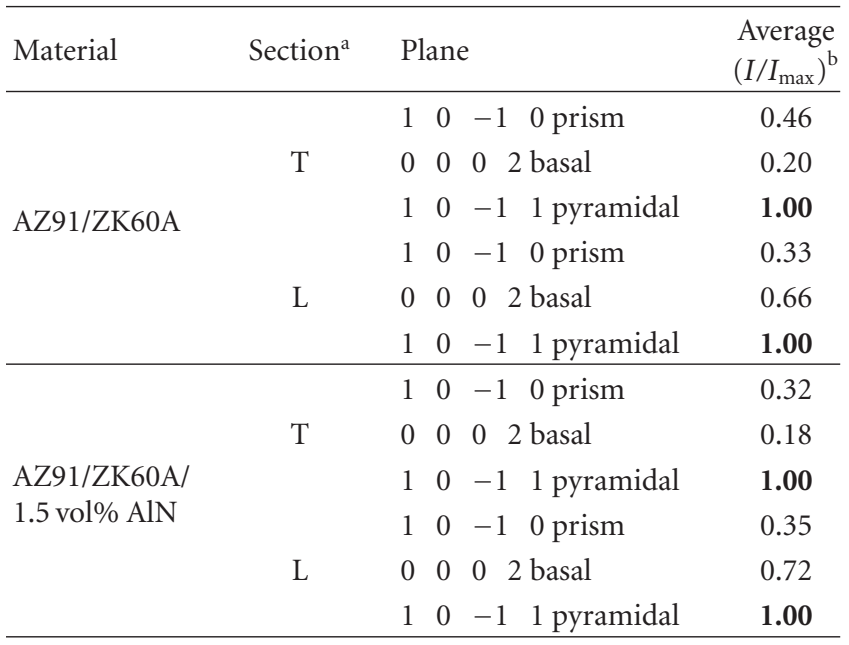

${ }^{\mathrm{a}} \mathrm{T}$ : transverse, L: longitudinal.

${ }^{\mathrm{b}} I_{\max }$ is XRD maximum intensity from either prism, basal or pyramidal planes.

TABLE 3: Results of tensile testing of AZ91/ZK60A and AZ91/ ZK60A/AlN nanocomposite.

\begin{tabular}{lcccc}
\hline Material & $\begin{array}{c}0.2 \% \text { TYS } \\
(\mathrm{MPa})\end{array}$ & $\begin{array}{c}\text { UTS } \\
(\mathrm{MPa})\end{array}$ & $\begin{array}{c}\text { Failure } \\
\text { Strain }(\%)\end{array}$ & $\begin{array}{c}\text { Energy } \\
\text { absorbed, } \\
\mathrm{EA}\left(\mathrm{MJ} / \mathrm{m}^{3}\right)^{\mathrm{a}}\end{array}$ \\
\hline AZ91/ZK60A & $225 \pm 4$ & $321 \pm 4$ & $16.1 \pm 0.3$ & $49 \pm 1$ \\
AZ91/ZK60A/ & $236 \pm 6$ & $336 \pm 4$ & $13.8 \pm 1.0$ & $44 \pm 4$ \\
1.5 vol\% AlN & $(+5)$ & $(+5)$ & $(-14)$ & $(-10)$ \\
\hline
\end{tabular}

${ }^{a}$ Energy absorbed until fracture, that is, area under the engineering stressstrain curve until the point of fracture (obtained using EXCEL software). () Brackets indicate \% change with respect to corresponding result of AZ91/ ZK60A.

TABLE 4: Results of compressive testing of AZ91/ZK60A and AZ91/ ZK60A/AlN nanocomposite.

\begin{tabular}{lcccc}
\hline Material & $\begin{array}{c}0.2 \% \text { CYS } \\
(\mathrm{MPa})\end{array}$ & $\begin{array}{c}\text { UCS } \\
(\mathrm{MPa})\end{array}$ & $\begin{array}{c}\text { Failure } \\
\text { Strain }(\%)\end{array}$ & $\begin{array}{c}\text { Energy } \\
\text { absorbed, } \\
\mathrm{EA}\left(\mathrm{MJ} / \mathrm{m}^{3}\right)^{\mathrm{a}}\end{array}$ \\
\hline AZ91/ZK60A & $106 \pm 5$ & $508 \pm 17$ & $19.5 \pm 1.7$ & $83 \pm 9$ \\
AZ91/ZK60A/ & $\begin{array}{c}107 \pm 12 \\
(+1)\end{array}$ & $\begin{array}{c}541 \pm 19 \\
(+6)\end{array}$ & $\begin{array}{c}24.1 \pm 6.5 \\
(+24)\end{array}$ & $88 \pm 7(+6)$ \\
$1.5 \mathrm{vol} \%$ AlN & &
\end{tabular}

${ }^{a}$ Energy absorbed until fracture, that is, area under the engineering stressstrain curve until the point of fracture (obtained using EXCEL software). () Brackets indicate \% change with respect to corresponding result of AZ91/ZK60A.

computing the area under the stress-strain curve up to the point of fracture.

3.5. Compressive Behavior. The overall results of ambient temperature compressive testing of the extruded materials are shown in Table 4 and Figure 4(b). Comparing AZ91/ ZK60A/1.5 vol\% AlN to monolithic AZ91/ZK60A, yield strength was unchanged and ultimate strength, failure strain, and EA were each higher. 


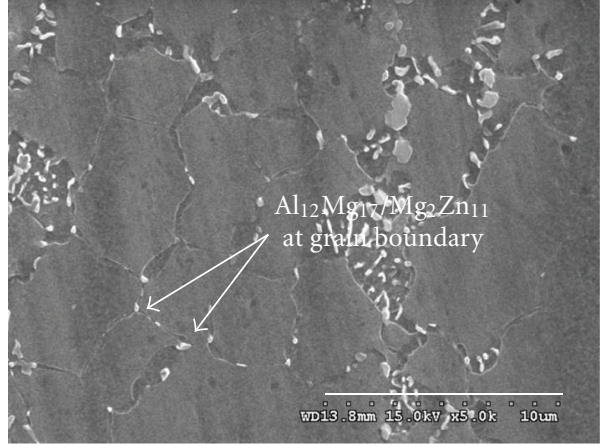

(a)
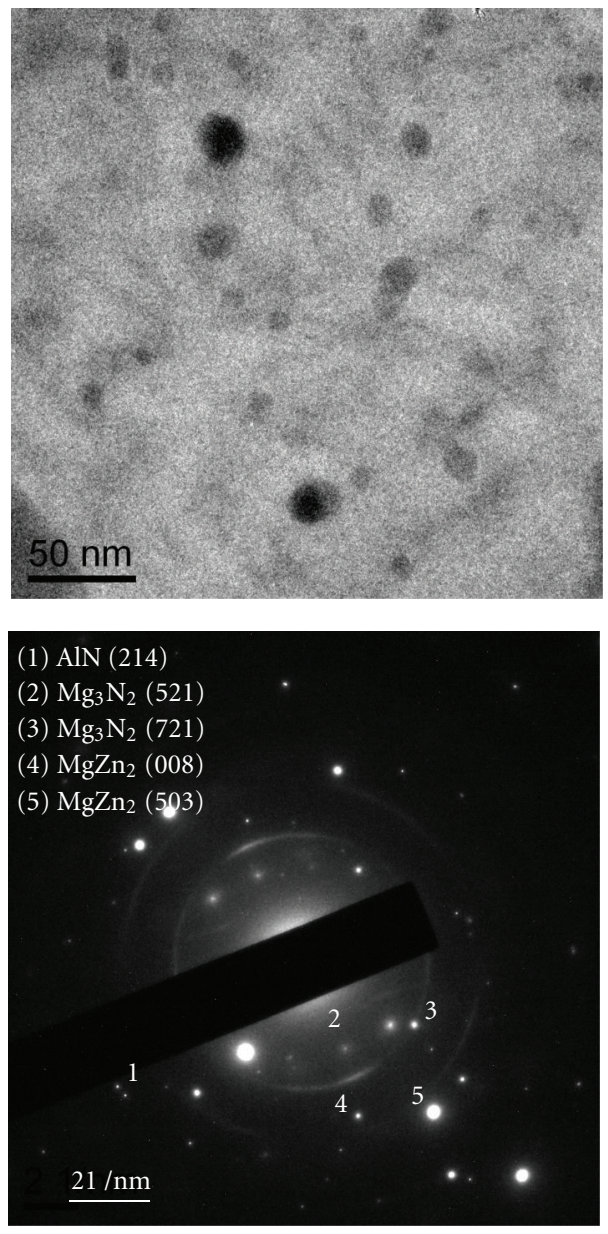

(c)

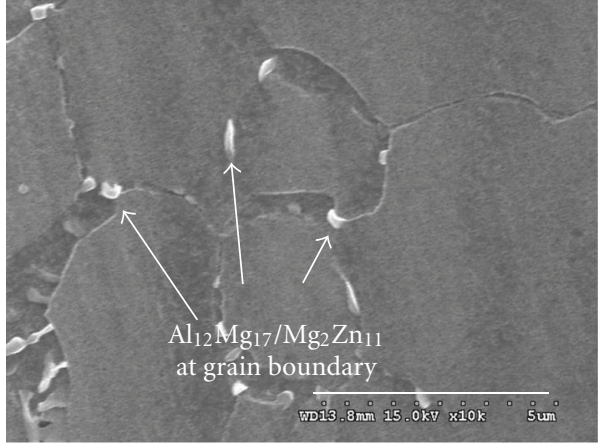

(b)
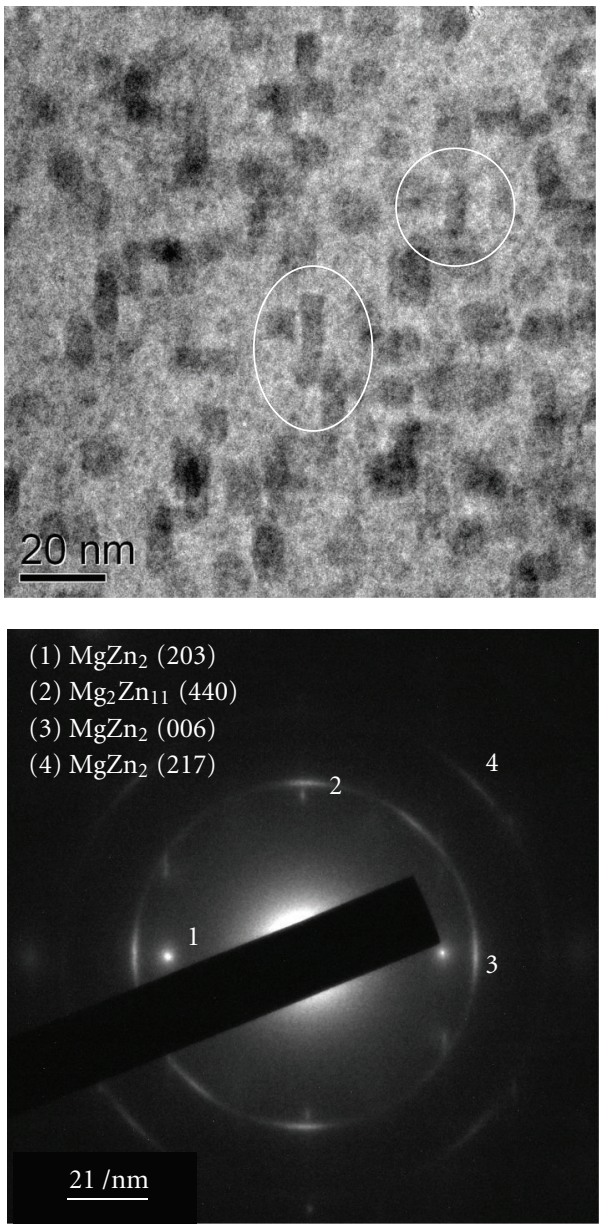

(d)

FIGURE 2: Representative FESEM micrographs showing grain size in monolithic AZ91/ZK60A and AZ91/ZK60A/AlN nanocomposite: (a) lower magnification and (b) higher magnification. (c) Representative TEM micrograph (including SAED pattern) showing the presence of individual nitride nanoparticles and fine intermetallic particles in AZ91/ZK60A/AlN nanocomposite. (d) Representative TEM micrograph (including SAED pattern) showing the presence of individual Mg-Zn rod-shaped nanoparticles in AZ91/ZK60A/AlN nanocomposite. Phases present but not labeled in the SAED patterns include $\mathrm{Mg}$ and $\mathrm{Mg}-\mathrm{Al}$ phases only.

\section{Discussion}

4.1. Synthesis of Monolithic AZ91/ZK60A and AZ91/ZK60A/ AlN Nanocomposite. Synthesis of monolithic and nanocomposite materials, the final form being extruded rods, was successfully accomplished with no detectable metal oxidation or reaction between graphite crucible and melts. The inert atmosphere used during DMD was effective in preventing oxidation of the $\mathrm{Mg}$ melt. No stable carbides of $\mathrm{Mg}$ or $\mathrm{Al}$ formed due to reaction with graphite crucible.

4.2. Microstructural Characteristics. Microstructural characterization of extruded samples is discussed in terms of (a) 


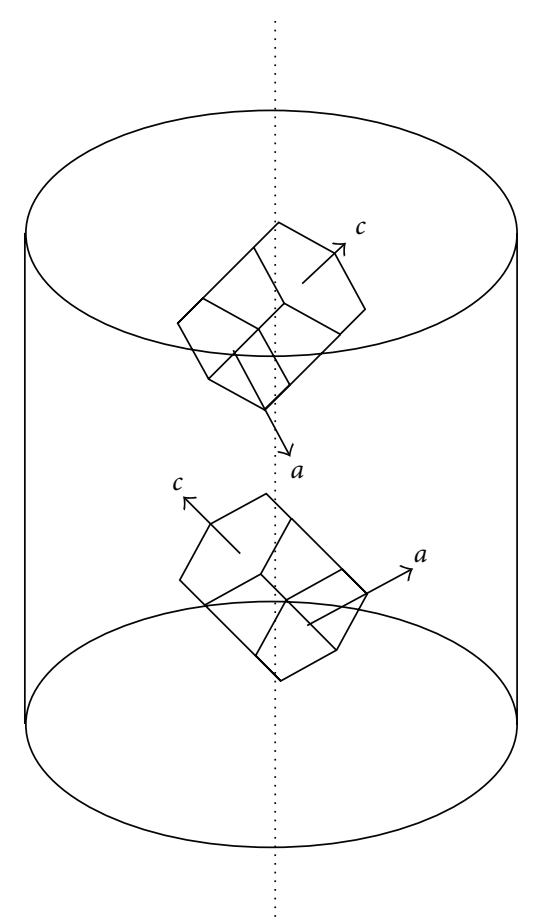

Figure 3: Schematic diagram showing textures of monolithic AZ91/ZK60A and AZ91/ZK60A/AlN nanocomposite based on goniometer X-ray diffraction. In each case, vertical axis (dotted line) is parallel to extrusion direction. Each cell is made up of $2 \mathrm{HCP}$ units having 1 common ( $\left.\begin{array}{llll}0 & 0 & 0 & 2\end{array}\right)$ basal splane.

grain characteristics and (b) AlN and intermetallic nanoparticle reinforcement distribution.

Nearly equiaxed grains were observed in monolithic material and nanocomposite as shown in Table 1 and Figures 2(a) and 2(b). Grain size was statistically unchanged in the case of nanocomposite, suggesting the inability of AlN nanoparticles to serve as either nucleation sites or obstacles to grain growth during solid state cooling. It was observed that $\mathrm{Al}_{12} \mathrm{Mg}_{17}$ and $\mathrm{Mg}_{2} \mathrm{Zn}_{11}$ intermetallic particles decorated the grain boundaries in the monolithic material and nanocomposite. Goniometer X-ray diffraction (XRD) analysis revealed the presence of $\mathrm{Al}_{12} \mathrm{Mg}_{17}$ and $\mathrm{Mg}_{2} \mathrm{Zn}_{11}$ phases [4, 11 . This was possibly due to near-homogenous (as opposed to total homogenous) mixing of AZ91 and ZK60A constituent alloys since the mixing time at $750^{\circ} \mathrm{C}$ before spray deposition was only a few minutes. $\mathrm{Al}_{12} \mathrm{Mg}_{17}$ and $\mathrm{Mg}_{2} \mathrm{Zn}_{11}$ intermetallic phases are commonly found in the individual AZ91 and ZK60A alloys, respectively [1].

The reasonably uniform distribution of AlN and intermetallic nanoparticles as shown in Figure 2(c) can be attributed to (a) minimal gravity-associated segregation due to judicious selection of stirring parameters [21], (b) good wetting of AlN nanoparticles by the alloy matrix [11,2224], (c) argon gas disintegration of metallic stream [25], and (d) dynamic deposition of composite slurry on substrate followed by hot extrusion. In the nanocomposite, selected area electron diffraction (SAED) in TEM revealed the (a) partial reaction of $\mathrm{AlN}$ with the $\mathrm{Mg}$ alloy matrix to form $\mathrm{Mg}_{3} \mathrm{~N}_{2}$ (see Figure 2(c)) and (b) the occurrence of Mg-Zn nanorods (not observed in the monolithic alloy, see Figure 2(d)). Regarding the occurrence of $\mathrm{Mg}-\mathrm{Zn}$ nanorods, the $\mathrm{Mg}-\mathrm{Zn}$ intermetallic phase(s) precipitation was possibly regulated at nanoscale due to the presence of well-dispersed AlN nanoparticles. Dissolved Zn possibly segregated at the liquid-AlN nanoparticle interface enabling $\mathrm{Mg}-\mathrm{Zn}$ intermetallic phase manipulation at the nanoscale. This is similar to possible dissolved $\mathrm{Zn}$ segregation at the liquid-SiC nanoparticle interface enabling nanoscale $\mathrm{MgZn}_{2}$ precipitation as recently reported [26]. With a reasonably uniform AlN distribution throughout the AZ91/ZK60A matrix, the nanoparticle-matrix interface area was ample for effectively regulated segregation of 4.80-6.20 wt.\% Zn (or 1.21-1.59 vol. \% Zn) as nanoscale $\mathrm{Mg}-\mathrm{Zn}$ precipitates. This was similar to that reported recently for selected ZK60A nanocomposites [12-14].

\subsection{Mechanical Behavior}

4.3.1. Hardness. A significant increase in microhardness by $17 \%$ was observed in the nanocomposite when compared to monolithic material as listed in Table 1 . This was consistent with earlier observations made on $\mathrm{Mg} / \mathrm{Al}_{2} \mathrm{O}_{3}, \mathrm{AZ31} /$ $\mathrm{C}_{60}$ and AZ31/MWCNT nanocomposites [16, 17, 27-29]. The increase in hardness of the nanocomposite in the present study can be attributed to (a) reasonably uniform distribution of harder AlN nanoparticles in the matrix and (b) higher constraint to localized matrix deformation during indentation due to the presence of nanoparticles [27, 28].

4.3.2. Tensile and Compressive Behavior. The tensile and compressive strengths of monolithic material and nanocomposite are listed in Tables 3 and 4 (and shown in Figures 4(a) and $4(\mathrm{~b})$ ), respectively. $0.2 \%$ TYS and UTS were enhanced by $5 \%$ each in AZ91/ZK60A/1.5 vol\% AlN compared to monolithic material. In comparison of compressive strengths, $0.2 \%$ CYS and UCS of AZ91/ZK60A/1.5 vol\% AlN were unchanged and higher by $6 \%$, respectively, compared to monolithic material. However, the compressive stress detected at any given strain was lower for AZ91/ZK60A/ $1.5 \mathrm{vol} \%$ AlN compared to monolithic AZ91/ZK60A as shown in Figure 4(b). The tensile strength increase in AZ91/ ZK60A/1.5 vol\% AlN compared to monolithic AZ91/ ZK60A can be attributed to the following well-known factors (pertaining to reinforcement): (a) dislocation generation due to elastic modulus mismatch and coefficient of thermal expansion mismatch between the matrix and reinforcement [2831], (b) Orowan strengthening mechanism [30-32], and (c) load transfer from matrix to reinforcement $[28,30]$. The lower compressive strength of AZ91/ZK60A/1.5 vol\% AlN compared to monolithic AZ91/ZK60A can be attributed possibly to compressive shear buckling of brittle $\mathrm{Mg}-\mathrm{Zn}$ nanorods in AZ91/ZK60A/1.5 vol\% AlN as illustrated in Figure 5. The compressive shear buckling of $\mathrm{Mg}$ - $\mathrm{Zn}$ nanorods induces a slightly lower limit on the factors pertaining to reinforcement (as just described).

In both AZ91/ZK60A/1.5 vol\% AlN and monolithic AZ91/ZK60A, 0.2\% TYS was about 2.21 and 2.12 times the $0.2 \%$ CYS, respectively. Here, the tensile/compressive yield 


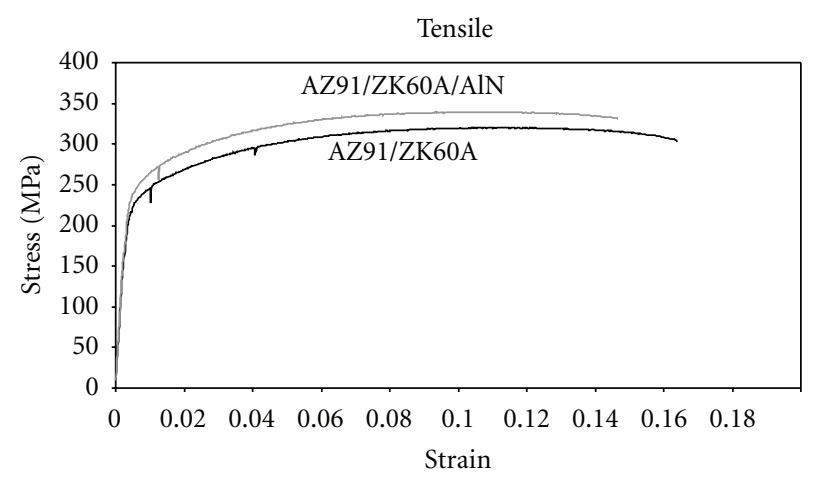

(a)

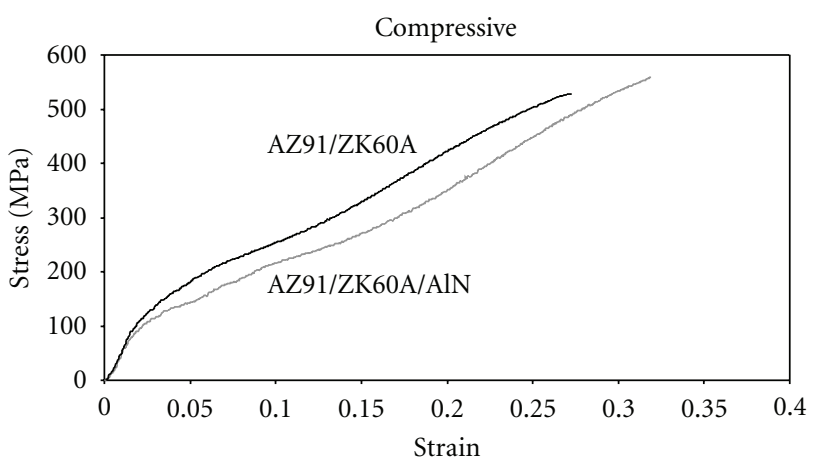

(b)

FIGURE 4: Representative: (a) tensile and (b) compressive stress-strain curves of monolithic AZ91/ZK60A and AZ91/ZK60A/AlN nanocomposite.

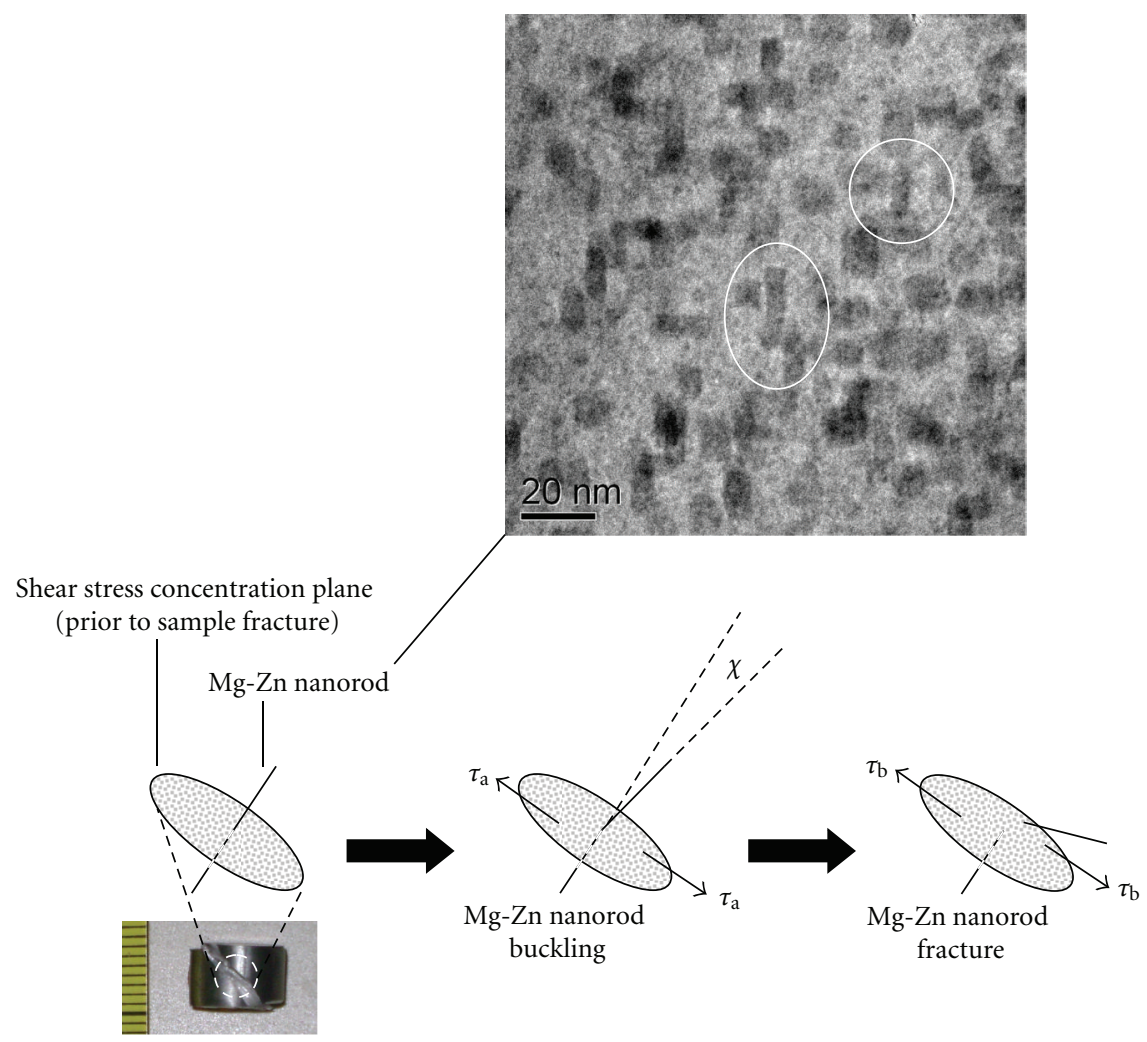

Shear fractured compression sample

FIGURE 5: Schematic diagram illustrating compressive shear buckling of brittle Mg-Zn nanorod (circled in TEM micrograph) in AZ91/ ZK60A/AlN nanocomposite. $\tau_{a}$ and $\tau_{b}$ represent planar shear stresses where $\tau_{a}<\tau_{b} \cdot \chi$ (exaggerated) represents very low angular deflection of the brittle $\mathrm{Mg}-\mathrm{Zn}$ nanorod during buckling.

stress anisotropy ( $0.2 \%$ TYS $/ 0.2 \%$ CYS) was present despite the crystallographic texture exhibited where $\left\{\begin{array}{llll}1 & 0 & 1 & -2\end{array}\right\}$ $\left\langle\begin{array}{llll}1 & 0 & 1 & -1\end{array}\right\rangle$-type twinning was activated along the $c$-axis of the HCP unit cell in Figure 3 with comparatively similar ease in both tension and compression along the $c$-axis, based on the $45^{\circ}$ angle between the $c$-axis and the vertical axis $[33,34]$. The tensile/compressive yield stress anisotropy $(0.2 \%$ TYS $/ 0.2 \%$ CYS $)$ can be attributed generally to half the strain rate used (less strain hardening) in compressive testing compared to tensile testing. The tensile/compressive yield stress anisotropy was slightly higher for AZ91/ZK60A/ 1.5 vol\% AlN compared to monolithic AZ91/ZK60A (2.21 compared to 2.12 , resp.). This was similar to that observed in the case of selected ZK60A nanocomposites compared to monolithic ZK60A [12-14]. This can be attributed possibly to compressive shear buckling of brittle $\mathrm{Mg}$ - $\mathrm{Zn}$ nanorods as 
illustrated in Figure 5. The brittle Mg-Zn nanorod is prone to buckling followed by fracture within the AZ91/ZK60A matrix during compressive deformation unlike during tensile deformation.

The tensile and compressive failure strains of monolithic material and nanocomposite are listed in Tables 3 and 4 (and based on stress-strain curves shown in Figures 4(a) and $4(\mathrm{~b}))$, respectively. Compared to monolithic material, tensile failure strain was slightly compromised $(-14 \%)$ in AZ91/ZK60A/1.5 vol\% AlN. Compared to monolithic material, compressive failure strain was higher $(+24 \%)$ in AZ91/ $\mathrm{ZK} 60 \mathrm{~A} / 1.5 \mathrm{vol} \% \mathrm{AlN}$. Both trends in failure strain of AZ91/ ZK60A/1.5 vol\% AlN compared to monolithic AZ91/ZK60A can be attributed to the presence of $\mathrm{Mg}-\mathrm{Zn}$ nanorods (not observed in monolithic AZ91/ZK60A) in AZ91/ZK60A/ 1.5 vol\% AlN (see Figure 2(d)). Regarding the trend in tensile failure strain, it has been shown in previous studies that the nanoparticles provide sites where cleavage cracks are opened ahead of the advancing crack front. This cleavage crack opening dissipates the stress concentration that would otherwise exist at the crack front and alters the local effective stress state from plane strain to plane stress in the neighbourhood of the crack tip [27, 35]. However, stress concentrations around the sharp ends of the $\mathrm{Mg}$ - $\mathrm{Zn}$ nanorods could not be effectively diffused by the surrounding near-spherical AlN or Mg-Al intermetallic nanoparticles. The trend in tensile failure strain can also be attributed to the partial reactivity between AlN nanoparticles and the $\mathrm{Mg}$ alloy matrix where $\mathrm{Mg}_{3} \mathrm{~N}_{2}$ was formed (see Figure 2(c)). Regarding the trend in compressive failure strain, compressive shear buckling of $\mathrm{Mg}-\mathrm{Zn}$ nanorods within the AZ91/ZK60A matrix (see Figure 5) aided in dispersing localized stored energy during compressive deformation. This allowed AZ91/ZK60A/1.5 vol\% AlN to globally absorb relatively large amounts of strain energy during compressive deformation [12, 36]. Here, Mg-Zn nanorod buckling within the AZ91/ZK60A matrix is a compressive toughening mechanism.

\section{Conclusions}

(i) Monolithic AZ91/ZK60A and AZ91/ZK60A/1.5 vol\% AlN nanocomposite can be successfully synthesized using the DMD technique followed by hot extrusion.

(ii) Compared to monolithic AZ91/ZK60A, tensile strength of AZ91/ZK60A/1.5 vol\% AlN was enhanced. This can be attributed to well-known factors pertaining to reinforcement. Compared to monolithic AZ91/ZK60A, compressive strength of AZ91/ ZK60A/1.5 vol\% AlN was decreased. This can be attributed possibly to compressive shear buckling of $\mathrm{Mg}-\mathrm{Zn}$ nanorods in the nanocomposite.

(iii) Compared to monolithic AZ91/ZK60A, tensile and compressive failure strains of AZ91/ZK60A/1.5 vol\% AlN were slightly compromised and enhanced, respectively. The slight compromise in tensile failure strain can be attributed to (a) stress concentrations around the sharp ends of the Mg- $\mathrm{Zn}$ nanorods not being effectively diffused by the surrounding nearspherical AlN or Mg-Al intermetallic nanoparticles and (b) partial reactivity between AlN nanoparticles and the $\mathrm{Mg}$ alloy matrix where $\mathrm{Mg}_{3} \mathrm{~N}_{2}$ was formed. The enhancement in compressive failure strain can be attributed to compressive shear buckling of $\mathrm{Mg}-\mathrm{Zn}$ nanorods in the AZ91/ZK60A matrix.

\section{Acknowledgments}

The authors wish to acknowledge National University of Singapore (NUS) and Temasek Defence Systems Institute (TDSI) for funding this research (TDSI/09-011/1A and WBS no. R265000349).

\section{References}

[1] M. M. Avedesian and H. Baker, ASM Specialty Handbook: Magnesium and Magnesium Alloys, ASM International, Novelty, Ohio, USA, 1999.

[2] J. G. Kaufman, Introduction to Aluminium Alloys and Tempers, ASM International, Materials Park, Ohio, USA, 2000.

[3] E. F. Emley, Principles of Magnesium Technology, Pergamon Press, Oxford, UK, 1966.

[4] M. Paramsothy, S. F. Hassan, N. Srikanth, and M. Gupta, "Enhancing tensile/compressive response of magnesium alloy AZ31 by integrating with $\mathrm{Al}_{2} \mathrm{O}_{3}$ nanoparticles," Materials Science and Engineering A, vol. 527, no. 1-2, pp. 162-168, 2009.

[5] M. Paramsothy, S. F. Hassan, N. Q. Bau, N. Srikanth, and M. Gupta, "Selective enhancement of tensile/compressive strength and ductility of AZ31 magnesium alloy via nano$\mathrm{Al}_{2} \mathrm{O}_{3}$ reinforcement integration method alteration," Materials Science Forum, vol. 618, pp. 423-427, 2009.

[6] M. Paramsothy, S. F. Hassan, N. Srikanth, and M. Gupta, "Simultaneous enhancement of tensile/compressive strength and ductility of magnesium alloy az31 using carbon nanotubes," Journal of Nanoscience and Nanotechnology, vol. 10, no. 2, pp. 956-964, 2010.

[7] M. Paramsothy, J. Chan, R. Kwok, and M. Gupta, "Carbon nanotube addition to simultaneously enhance strength and ductility of hybrid AZ31/AA5083 alloy," Materials Sciences \& Applications, vol. 2, pp. 20-29, 2011.

[8] M. Paramsothy, J. Chan, R. Kwok, and M. Gupta, "The synergistic ability of $\mathrm{Al}_{2} \mathrm{O}_{3}$ nanoparticles to enhance mechanical response of hybrid alloy AZ31/AZ91," Journal of Alloys and Compounds, vol. 509, no. 28, pp. 7572-7578, 2011.

[9] M. Paramsothy, J. Chan, R. Kwok, and M. Gupta, "Enhanced mechanical response of hybrid alloy AZ31/AZ91 based on the addition of $\mathrm{Si}_{3} \mathrm{~N}_{4}$ nanoparticles," Materials Science and Engineering A, vol. 528, no. 21, pp. 6545-6551, 2011.

[10] M. Paramsothy, J. Chan, R. Kwok, and M. Gupta, "TiC nanoparticle addition to enhance the mechanical response of hybrid magnesium alloy," Journal of Nanotechnology, vol. 2012, Article ID 401574, 2012.

[11] M. Paramsothy, J. Chan, R. Kwok, and M. Gupta, "The effective reinforcement of magnesium alloy ZK60A using $\mathrm{Al}_{2} \mathrm{O}_{3}$ nanoparticles," Journal of Nanoparticle Research, vol. 13, no. 10 , pp. 4855-4866, 2011.

[12] M. Paramsothy, J. Chan, R. Kwok, and M. Gupta, "Addition of CNTs to enhance tensile/compressive response of magnesium alloy ZK60A," Composites Part A, vol. 42, no. 2, pp. 180-188, 2011. 
[13] M. Paramsothy, J. Chan, R. Kwok, and M. Gupta, "Enhanced mechanical response of magnesium alloy ZK60A containing $\mathrm{Si}_{3} \mathrm{~N}_{4}$ nanoparticles," Composites Part A, vol. 42, no. 12, pp. 2093-2100, 2011.

[14] M. Paramsothy, J. Chan, R. Kwok, and M. Gupta, "Adding TiC nanoparticles to magnesium alloy ZK60A for strength/ ductility enhancement," Journal of Nanomaterials, vol. 2011, Article ID 642980, 2011.

[15] Y. Morisada, H. Fujii, T. Nagaoka, and M. Fukusumi, "Effect of friction stir processing with $\mathrm{SiC}$ particles on microstructure and hardness of AZ31," Materials Science and Engineering A, vol. 433, no. 1-2, pp. 50-54, 2006.

[16] Y. Morisada, H. Fujii, T. Nagaoka, and M. Fukusumi, "Nanocrystallized magnesium alloy-uniform dispersion of $\mathrm{C}_{60}$ molecules," Scripta Materialia, vol. 55, no. 11, pp. 1067-1070, 2006.

[17] Y. Morisada, H. Fujii, T. Nagaoka, and M. Fukusumi, "MWCNTs/AZ31 surface composites fabricated by friction stir processing," Materials Science and Engineering A, vol. 419, no. 1-2, pp. 344-348, 2006.

[18] C. J. Lee, J. C. Huang, and P. J. Hsieh, "Mg based nano-composites fabricated by friction stir processing," Scripta Materialia, vol. 54, no. 7, pp. 1415-1420, 2006.

[19] L. M. Tham, M. Gupta, and L. Cheng, "Influence of processing parameters during disintegrated melt deposition processing on near net shape synthesis of aluminium based metal matrix composites," Materials Science and Technology, vol. 15, no. 10, pp. 1139-1146, 1999.

[20] M. Gupta, M. O. Lai, and S. C. Lim, "Regarding the processing associated microstructure and mechanical properties improvement of an Al-4.5 Cu alloy," Journal of Alloys and Compounds, vol. 260, no. 1-2, pp. 250-255, 1997.

[21] L. M. Tham, M. Gupta, and L. Cheng, "Influence of processing parameters during disintegrated melt deposition processing on near net shape synthesis of aluminium based metal matrix composites," Materials Science and Technology, vol. 15, no. 10, pp. 1139-1146, 1999.

[22] B. Q. Han and D. C. Dunand, "Microstructure and mechanical properties of magnesium containing high volume fractions of yttria dispersoids," Materials Science and Engineering A, vol. 277, no. 1-2, pp. 297-304, 2000.

[23] N. Eustathopoulos, M. G. Nicholas, and B. Drevet, Wettability at High Temperatures, Vol. 3, Pergamon Materials Series, Pergamon, New York, NY, USA, 1999.

[24] J. D. Gilchrist, Extraction Metallurgy, Pergamon Press, New York, NY, USA, 3rd edition, 1989.

[25] M. Gupta, M. O. Lai, and C. Y. Soo, "Effect of type of processing on the micro structural features and mechanical properties of $\mathrm{Al}-\mathrm{Cu} / \mathrm{SiC}$ metal matrix composites," Materials Science and Engineering A, vol. 210, no. 1-2, pp. 114-122, 1996.

[26] M. De Cicco, H. Konishi, G. Cao et al., "Strong, ductile magnesium-zinc nanocomposites," Metallurgical and Materials Transactions A, vol. 40, no. 12, pp. 3038-3045, 2009.

[27] S. F. Hassan and M. Gupta, "Effect of particulate size of $\mathrm{Al}_{2} \mathrm{O}_{3}$ reinforcement on microstructure and mechanical behavior of solidification processed elemental Mg," Journal of Alloys and Compounds, vol. 419, no. 1-2, pp. 84-90, 2006.

[28] S. F. Hassan and M. Gupta, "Effect of different types of nanosize oxide participates on microstructural and mechanical properties of elemental Mg," Journal of Materials Science, vol. 41, no. 8, pp. 2229-2236, 2006.

[29] S. F. Hassan and M. Gupta, "Enhancing physical and mechanical properties of $\mathrm{Mg}$ using nanosized $\mathrm{Al}_{2} \mathrm{O}_{3}$ particulates as reinforcement," Metallurgical and Materials Transactions A, vol. 36, no. 8, pp. 2253-2258, 2005.

[30] Z. Száraz, Z. Trojanová, M. Cabbibo, and E. Evangelista, "Strengthening in a WE54 magnesium alloy containing SiC particles," Materials Science and Engineering A, vol. 462, no. 1-2, pp. 225-229, 2007.

[31] L. H. Dai, Z. Ling, and Y. L. Bai, "Size-dependent inelastic behavior of particle-reinforced metal-matrix composites," Composites Science and Technology, vol. 61, no. 8, pp. 10571063, 2001.

[32] D. Hull and D. J. Bacon, Introduction to Dislocations, Butterworth-Heinemann, Oxford, UK, 4th edition, 2002.

[33] T. Laser, C. Hartig, M. R. Nürnberg, D. Letzig, and R. Bormann, "The influence of calcium and cerium mischmetal on the microstructural evolution of $\mathrm{Mg}-3 \mathrm{Al}-1 \mathrm{Zn}$ during extrusion and resulting mechanical properties," Acta Materialia, vol. 56, no. 12, pp. 2791-2798, 2008.

[34] J. Bohlen, S. B. Yi, J. Swiostek, D. Letzig, H. G. Brokmeier, and K. U. Kainer, "Microstructure and texture development during hydrostatic extrusion of magnesium alloy AZ31," Scripta Materialia, vol. 53, no. 2, pp. 259-264, 2005.

[35] S. F. Hassan and M. Gupta, "Development of nano- $\mathrm{Y}_{2} \mathrm{O}_{3}$ containing magnesium nanocomposites using solidification processing," Journal of Alloys and Compounds, vol. 429, no. 1-2, pp. 176-183, 2007.

[36] S. Namilae and N. Chandra, "Role of atomic scale interfaces in the compressive behavior of carbon nanotubes in composites," Composites Science and Technology, vol. 66, no. 13, pp. 20302038, 2006. 

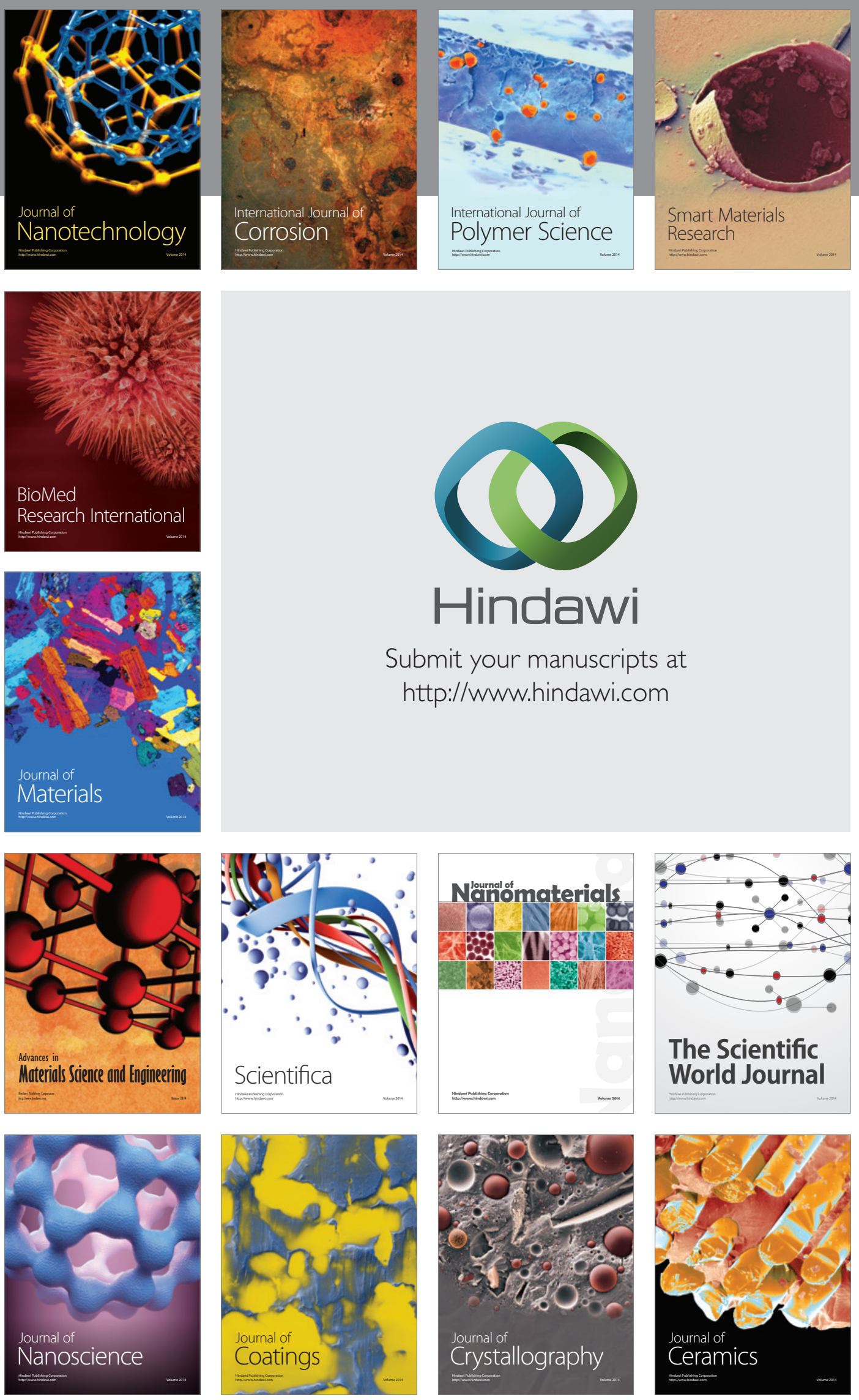

The Scientific World Journal

Submit your manuscripts at

http://www.hindawi.com

\section{World Journal}

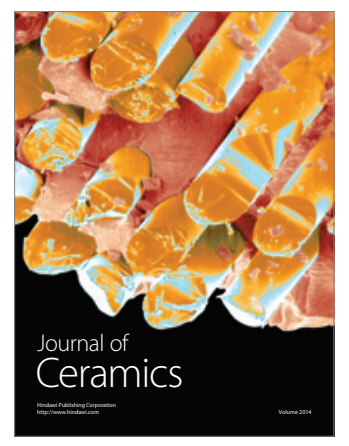

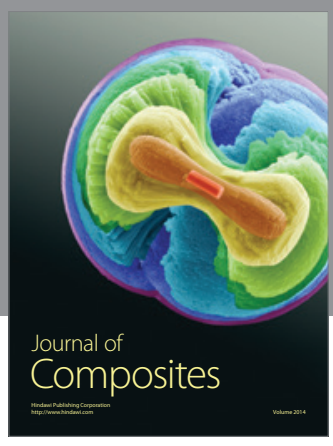
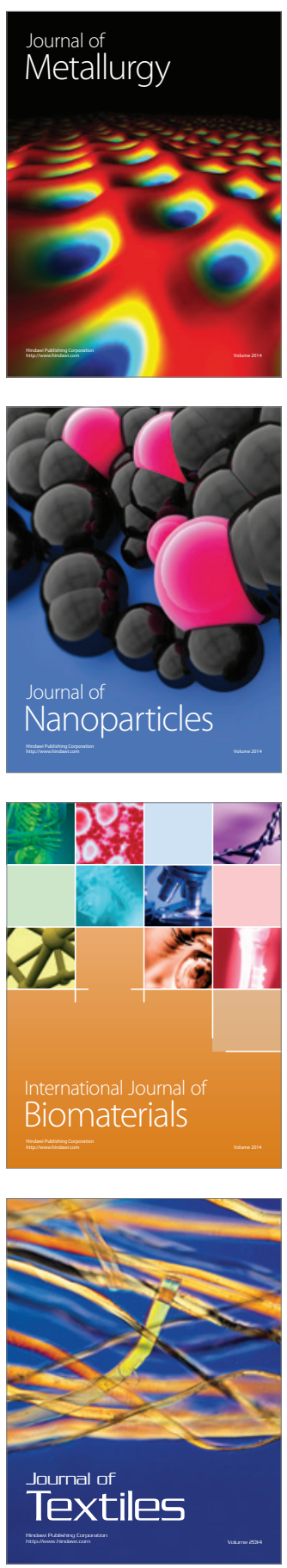